\title{
EFEK PENULARAN COVID-19 BAGI USAHA MIKRO KECIL (UMK) PERSPEKTIF UNDANG-UNDANG CIPTA KERJA
}

\author{
Stephanie PD ${ }^{1}$, Enjelina $\mathrm{S}^{2}$, Natasha $\mathrm{OA}^{3}$, Jeane Netlje Sally ${ }^{4}$ \\ ${ }^{1}$ Jurusan Hukum, Universitas TarumanagaraJakarta \\ ${ }^{l}$ Email: stephanieuntar@gmail.com \\ ${ }^{2}$ Jurusan Hukum, Universitas TarumanagaraJakarta \\ ${ }^{2}$ Email: enjellsummerlee@gmail.com \\ ${ }^{3}$ Jurusan Hukum, Universitas TarumanagaraJakarta \\ ${ }^{3}$ Email: natashaolivia979@yahoo.com \\ ${ }^{4}$ Jurusan Hukum, Universitas TarumanagaraJakarta \\ Email: jeanes@fh.untar.ac.id
}

\begin{abstract}
Pagebluk corona resulted in a critical health condition of the public and disrupted the economy of the archipelago. The impact of the corona pagebluk in Indonesia; business sector, especially the Micro Small Business (UMK) sector. Some MSE actors have difficulty paying debts and employee salaries and even fire their employees, funding difficulties so that they are constrained in buying raw materials, declining buyers, closed access so that distribution and production are hampered. Micro and Small Enterprises (UMK) are the most important pillars in the Indonesian economy. The large number of Indonesian MSEs is related to all the obstacles in the field, especially during the Covid-19 pandemic. The normative legal method is used in this study, the focus is on "secondary data" covering primary; secondary; tertiary legal materials. Qualitative approach with descriptive research nature. The government's efforts to raise the MSE class for a long-term strategy through the CK Law. A legal entity business unit makes it easier for MSEs to run their business. This makes it easier for MSEs to get capital assistance from banks. With the help of definite capital, it will be easier for his business to develop. In order to survive and develop, MSEs make several legal efforts, register their businesses, obtain halal permits and certificates, register brands, make cooperation agreements with relevant agencies, form or join MSE organizations. MSEs as the biggest supporter of the economy must receive special attention from the Indonesian government, so that they can become masters in their own country. All matters relating to government policies in tackling COVID-19 must consider the economic aspect, so as to avoid a deep downturn in MSEs actors.
\end{abstract}

Keywords: pandemic,Covid-19, Micro and Small Entreprise, legal efforts.

\section{ABSTRAK}

Pagebluk corona mengakibatkan kegentingan kondisi sehat khalayak dan mengacaukan perekonomian nusantara. Imbas pagebluk corona di Indonesia; bidang bisnis, terutama sektor Usaha Mikro Kecil (UMK). Beberapa pelaku UMK mengalami kesulitan membayar hutang dan gaji karyawan bahkan memecat karyawannya, kesulitan pendanaan sehingga terkendala dalam membeli bahan baku, menurunnya pembeli, tertutupnya akses sehingga penyaluran dan produksi terhambat. Usaha Mikro Kecil (UMK) merupakan pilar terpenting dalam perekonomian Indonesia. Banyaknya UMK Indonesia berkaitan dengan segala hambatan di lapangan, terutama dimasa pandemi covid-19. Menggunakan metode hukum normatif, fokusnya "data sekunder" meliputi "bahan hukum primer;sekunder;tersier". Pendekatan kualitatif dengan sifat penelitian deskriptif. Upaya pemerintah untuk menaikkan kelas UMK untuk strategi jangka panjang melalui UU CK. Unit usaha berbadan hukum memudahkan UMK menjalankan usahanya. Sehingga memudahkan UMK mendapat bantuan modal dari bank. Dengan bantuan permodalan yang pasti maka usahanya akan lebih mudah berkembang. Agar dapat survive dan berkembang UMK melakukan beberapa upaya hukum, mendaftarkan usahanya, mendapatkan perijinan dan sertifikat halal, mendaftarkan merek, membuat perjanjian kesepakatan kerjasama dengan instansi terkait, membentuk atau bergabung dalam organisasi UMK. UMK sebagai pendukung perekonomian terbesar harus mendapat perhatian khusus dari pemerintah Indonesia, sehingga bisa menjadi tuan di negerinya sendiri. Segala hal yang berhubungan dengan kebijaksanaan pemerintah dalam menanggulangi cov-19 harus mempertimbangkan segi ekonomi, sehingga menghindari keterpurukan mendalam pelaku UMK.

Kata Kunci: pandemi, Covid-19, UMK, upaya hukum. 


\section{PENDAHULUAN}

\section{Latar Belakang}

Dampak pandemi covid-19, merupakan salah satu kendala dari beragam gangguan yang menghambat tujuan kegiatan usaha, antara lain Usaha Mikro Kecil (UMK). Untuk menggenapi hak pendidikan dan penghidupan yang seimbang melalui UUCK, pemerintah menjalankan bermacammacam berbagai ikhtiar. Dasar pelaksanaannya dibuat pada aturan UUCK No.11 membahas Cipta Kerja (UU CK) yang mepersiapkan peluang bagi UMK agar dapat lebih berperan dalam berusaha sebagai implementasi dari sila kelima Pancasila yaitu keadilan sosial. Hal itu diatur dalam Pasal Pasal 153, Pasal 153A-153J UU CK yang memberikan kesempatan bagi UMK untuk mendirikan Perseroan.

Pengertian UMK dalam UU CK adalah Usaha Mikro, Kecil (Pasal 1 angka 3 UU CK). Menurut UU No. 20/2008 ialah "usaha perdagangan yang dijalankan oleh badan usaha atau perorangan yang merujuk pada usaha perekonomian produktif sesuai dengan kriteria yang ditentukan" "(1) Usaha mikro yaitu usaha produktif milik badan usaha yang sudah diatur aturannya di perundangan”. "(2)Usaha Kecil yaitu usaha ekonomi produktif mandiri dan dilakukan oleh perorangan dan atau bukan merupakan bagian/anak perusahaan yang dikuasai, dimiliki atau bagian langsung atau tidak langsung dari usaha sedang atau usaha besar yang memenuhi kriteria usaha kecil yang sudah diatur aturannya didalam perundangan”.

Tabel 1. Kriteria UMK berdasarkan Asset dan Omset

\begin{tabular}{|c|c|c|c|}
\hline \multirow{2}{*}{ No } & \multirow{2}{*}{ Uraian } & \multicolumn{2}{|c|}{ Kriteria } \\
\cline { 3 - 4 } & & $\begin{array}{c}\text { Asset } \\
\text { tidak termasuk tanah \& bangunan } \\
\text { tempat usaha }\end{array}$ & $\begin{array}{c}\text { Omzet } \\
\text { (dalam 1 tahun) }\end{array}$ \\
\hline \multirow{2}{*}{1} & Usaha Mikro & Maksimal & Maksimal \\
\hline \multirow{2}{*}{2} & Usp.50.000.000,00 & Rp. $300.000 .000,00$ \\
\hline
\end{tabular}

Sumber: UU No.20/2008 Tentang Usaha Mikro dan Kecil

Walaupun upaya sudah dilakukan pemerintah melalui kesempatan UMK mendirikan Perseroan berbadan hukum, namun perwujudannya belum optimal. Hasil lembaga survei seperti BPS, Bappenas \& Bank Dunia menunjukkan selama pandemi banyak UMK mengalami kendala. Kendala tersebut antara lain, tidak mampu membayar hutang, elpiji, tagihan listrik juga pegawai. tidak sedikit yang mem-PHK. Kendala lain juga terjadi semisal kesulitan memperoleh bahan baku karena tertutupnya akses, kesulitan pendanaan, menurunnya pembeli, penyaluran dan produksi terhambat (Bahtiar, 2021).

Sesuai uraian yang sudah dijelaskan di latar belakang, maka penulis mengidentifikasikan rumusan permasalahan menjadi:

1) Bagaimana efek penularan covid-19 terhadap Usaha Mikro Kecil (UMK)?

2) Bagaimana upaya hukum yang dilakukan agar pelaku UMK dapat bertahan dan /atau berkembang pada masa pandemi covid-19 perspektif Undang-Undang Cipta Kerja? 


\section{METODE PENELITIAN}

Artikel memakai penelitian model "hukum normatif" dengan fokus di "data sekunder" (bahan hukum primer;sekunder;tersier) (Soekanto \& Mamudji, (2021)). Yang meliputi bahan hukum primer (UU CK, UU PT, PP 8/2021), bahan hukum sekunder (buku, jurnal, artikel) juga bahan hukum tersier (kamus). Sifat dari penelitian ini deskriptif dengan menggunakan pendekatan kualitatif untuk mendapatkan pemahaman gejala-gejala dari yang diteliti. Semua bahan hukum yang ada disortir, dirinci secara detail dan dijabarkan kemudian dihubungkan dengan peraturan perundangan terkait.

\section{HASIL DAN PEMBAHASAN}

\section{a. Dampak Pandemi covid-19 Terhadap Usaha Mikro Kecil (UMK)}

Pandemi Corona hampir berjalan 2 (dua) tahun berdampak pada tatanan kehidupan masyarakat dunia. Indonesia juga merasakan dampak pandemi covid-19 terutama pada bidang perekonomian, manufaktur, dan Usaha Mikro Kecil (UMK). Sektor UMK mayoritas pelakunya adalah warga menengah ke bawah terkena imbas yang sangat besar akibat pandemi ini. Sebagai donatur tertinggi "PDB" \& bisa diandalkan dalam menyerap kepegawaian, mensubstitusi produk setengah jadi, maka dalam kondisi krisis ekonomi karena pandemi yang berkepanjangan, sektor UMK perlu diperhatikan pemerintah.

Sejumlah persoalan klasik yang membelit UMK, diantaranya permodalan, hutang yang tidak dapat dilunasi, peizinan tidak dilakukan, distribusi terkendala, database \& peluang proyek pemerintah. Kenyataan bahwa perundangan perihal UMK terbagi pada bermacam-macam aturan UU, berdampak ditersebar dalam berbagai peraturan perundang-undangan, sehingga berimplikasi pada skema penguatan UMK yang terurai, tidak tertulis lengkap \& terkendalanya investasi.

Padahal kehadiran UMK dianggap menjadi potensi dasar yang bisa memberikan kontribusi besar bagi perekonomian Indonesia. Pada pandemi saat ini peluang UMK untuk terus bisa berkembang masih cukup luas dikarenakan tidak adanya keterbatasan bidang, usaha bidang apa saja bisa menjadi peluang bisnis UMK, namun di masa Pandemi covid-19 para pelaku UMK di tuntun untuk terus berinovasi untuk menciptakan sesuatu yang bukan hanya sekedar menjadi kebutuhan masyarakat saja. UMK diharapkan mampu untuk melihat dan memberdayakan berbagai jejaring sosial menjadi program pemasaran guna untuk meningkatkan usaha UMK (Sibarani,2020).

Memberdayakan UMK merupakan salah satu langkah pemulihan ekonomi nasional oleh pemerintah saat pandemi. Upaya tersebut dilakukan dikarenakan banyaknya penyerapan pegawai, pemerataan ekonomi wong cilik, media pengetas kemiskinan juga meningkatkan devisa, Perhatikan tabel 2 usaha mikro paling tinggi komposisinya karena bersingungan langsung dengan sosmas. Namun demikian pada tataran pelaksanaan atau operasionalnya terkena dampak pandemi covid-19. Beragam aspek menghalangi perkembangan bisnis UMK. 


\begin{tabular}{|c|c|c|c|c|c|c|c|c|}
\hline \multirow{2}{*}{ No } & \multirow{2}{*}{ INDIKATOR } & \multirow{2}{*}{ SATUAN } & \multicolumn{2}{|c|}{ TAHUN 2018} & \multicolumn{2}{|c|}{ TAHUN 2019} & \multicolumn{2}{|c|}{ TAHUN 2021} \\
\hline & & & JUMLAH & PANGSA (\%) & JUMLAH & PANGSA (\%) & JUMLAH & PANGSA $(\%)$ \\
\hline 1 & 2 & 3 & 4 & 5 & 6 & 7 & 10 & 11 \\
\hline 1 & UNIT USAHA (A-B) & (Unit) & $64,199,606$ & & $65,471,134$ & & & \\
\hline & A. Usaha Mikro, Kecil dan Menengah (UMKM) & (Unit) & $64,194,057$ & 99,99 & $65,465,479$ & 99,99 & $64,200,000$ & 99,99 \\
\hline & -Usaha Mikro (UM) & (Unit) & $63,350,222$ & 98,68 & $64,601,352$ & 98,67 & $63,960,000$ & 99,62 \\
\hline & -Usaha Kecil (UK) & (Unit) & 783,132 & 1,22 & 798,679 & 1,22 & 193,960 & 0,30 \\
\hline & -Usaha Menengah (UM) & (Unit) & 60,702 & 0,09 & 65,465 & 0,10 & 44,728 & 0,07 \\
\hline & B. Usaha Besar (UB) & (Unit) & 5,550 & 0,01 & 5,637 & 0,01 & 5,550 & 0,01 \\
\hline
\end{tabular}

Menunjukkan penurunan jumlah UMK pada 2021. Resiko besar pandemi berkepanjangan menghalangi perkembangan bisnis UMKM. Sejak diberlakukannya aturan pemerintah tentang menjaga jarak, mengurangi aktivitas dan menjauhi kerumunan, dan adanya aturan social distancing menjadikan ruang pamer atau promosi para bisnis UMKM semakin sempit (Marlina,2020). Pemerintah menilai bahwa dijalankannya "PSBB (pembatasan Sosial Berskala Besar) hingga PPKM (Pemberlakuan Pembatasan Kegiatan Masyarakat)" dianggap bisa menanggulangi penyebaran covid-19 yang sudah menyebar luas di kalangan masyarakat desa maupun masyarakat yang tinggal di kota besar. Akibat covid-19 perekonomian Indonesia berada dilevel ketidakpastian,

Program dukungan pemerintah bagi UMK. Diantaranya "Pemulihan Ekonomi Nasional/PEN yaitu subsidi diberikan pemerintah pada UMK, KUR/Kredit Usaha Rakyat, "Gerakan Nasional Bangga Buatan Indonesia (Gernas BBI)", "Digitalisasi pemasaran UMKM", "Penguatan Wirausaha Alumni Program Kartu Prakerja"). Untuk strategi jangka panjang bagi perkembangan UMK, pemerintah membentuk Undang-Undang Cipta Kerja (Kementrian, 2021).

Dengan adanya upaya pemerintah melakukan vaksinasi covid-19 sehingga terjadi pengurangan yang baru terinfeksi maupun kasus aktif cov-19. Adanya hari besar keagamaan berdampak peningkatan pembuatan barang guna pemenuhan kebutuhan rakyat, adanya panen raya yang mengakibatkan naiknya harga komoditas, adanya pelonggaran oleh pemerintah dibidang properti, pembelian rumah baru juga otomotif. Hal ini berdampak meningkatkan kegiatan perdagangan \& harapan perkembangan bidang UMK meningkat pada kwartal 1 tahun 2021. (Bahtiar, 2021)

\section{b. Upaya Hukum Guna Pelaku UMK Dapat Bertahan Dan /Atau Berkembang Pada Masa Pandemi Covid-19}

Upaya hukum yang dilakukan pemerintah agar UMK dapat bertahan dan/atau berkembang di pandemi covid-19 adalah membentuk UUCK. Upaya tersebut sebagai jalan keluar dari sejumlah persoalan klasik yang membelit UMK, diantaranya pembiayaan, pengesahan, marketing, sistem database \& jalur pengadaan pemerintah, disertai pengaturan UMK yang bertebaran dalam beragam aturan UU, berakibat sulit berkembang berakibat pada skema pemantapan UMK yang terurai, tidak ekstensif \& menghalangit penanamn modal. UU Ciptaker banyak mengakomodir kepentingan dasar yang dibutuhkan oleh UMKM, sebaik apapun dari bentuk dan tujuan UUCK juga diimbangi oleh pelaku UMK yang menjalankan UU tersebut, agar bisa efektif mencapai tujuannya. Dengan UUCK akan menguatkan UMK agar maju tumbuh \& berjaya juga punya kapabilitas bersaing yang handal sebagai tonggak kebangkitan UMK.

Tujuan pemerintah membentuk UUCK untuk memudahkan iklim berusaha di Indonesia sehingga terbuka lapangan pekerjaan yang seluas-luasnya, terutama dalam memangkas birokrasi yang berbelit 
sehingga diharapkan mampu untuk mempermudah berusaha (EoDB)), khususnya bagi pelaku Usaha Mikro Kecil (UMK). Hal itu tertuang dalam Pasal 153A(1) yang menyatakan "Perseroan yang memenuhi kriteria Usaha Mikro dan Kecil dapat didirikan oleh perorangan" Memberikan kemudahan bagi UMK untuk mendirikan usahanya tercantum pada Pasal 153B Ayat (2) hanya dengan mendaftarkan secara online pada laman Kemenkumham. Pasal 153J ayat (1) untuk memberikan payung hukum UMK dalam menjalankan usahanya pelaku UMK tidak berkewajiban secara personal pada usaha yang dibangunnya juga tidak melibatkan harta pribadi jika terjadi kerugian atau pailit. Ayat (2) mengupas perihal persyaratan sebagai badan hukum tidak terpenuhi jika memanfaatkan pendirian usaha untuk kepentingan pribadi, pelaku UMK cacat hukum, secara langsung atau tidak langsung dengan cara melawan hukum menggunakan asset perusahaan sehingga berakibat tidak cukup dalam membayar hutang.

Pemulihan UMK sebagai tanda positif semakin membaiknya ekonomi nasional yang tertekan akibat pandemi berkepanjangan. BTI Micro \& SME IndexUMK semakin optimis dengan prospek usahanya yang ditujukan dengan "BMSI" terkini terdeteksi adanya peningkatan bermakna Indeks Aktivitas Bisnis/IAB", "Indeks Ekspektasi Aktivitas Bisnis/IEAB" dan "Indeks Sentimen Bisnis/ISB" tiap kwartal 2021 dibanding kwartal IV tahun 2020. Hasil riset menunjukkan meningkatnya BMSI jadi 93,0 awalnya 81,5 Kwartal IV/ tahun 2020. Naiknya indeks ekspektasi BMSI jadi 128,0 pada 2021 awalnya 105,4 kwartal IV/2020. Sehubungan dengan kenaikan BMSI \& harapannya, secara umum tanggapan pelaku bisnis. ISB UMK naik drastis jadi 115,5 pada 2021 awalnya 90,2 kwartal IV/ 2020. Peningkatan IAB, IEAB, ISB pertanda dimulainya pegerakan kegiatan ekonomi UMK, tergambar adanya harapan hari esok yang lebih baik.(Bahtiar, 2021)

Kefektifan UUCK terukur pada kenaikan BMSI, IAB, IEAB dan ISB per kwartal 2021 dibanding kwartal IV/2020 akan berjalan maksimal jika didukung dengan pembiayaan, pengesahan, pendistribusian, pengorganisasian-data dan jalur khusus tender Goverment project maka UMK akan tumbuh dan berkembang.

Pengupayaan pemerintah merubah definisi Perseroan Terbatas/PT yang tercantum dalam UU PT (UU 40/2007) kedalam UU Ciptaker halaman 608 Pasal 109 Ayat 1 Pasal (1) "Perseroan Terbatas, yang selanjutnya disebut Perseroan, adalah badan hukum yang merupakan persekutuan modal, didirikan berdasarkan perjanjian, melakukan kegiatan usaha dengan modal dasar yang seluruhnya terbagi dalam saham atau Badan Hukum perorangan yang memenuhi kriteria Usah Mikro dan Kecil sebagaimana diatur dalam peraturan perundang-undangan mengenai Usaha Mikro dan Kecil" Tercantum kalimat UMK dalam definisi tersebut hal ini untuk memberikan kemudahan bagi UMK dalam melakukan upaya hukum selama masa pandemi berlangsung sehingga bisa bertahan bahkan berkembang. Untuk memudahkan pelaksanaan pasal-pasal UU Ciptaker yang terkait dengan perlindungan hukum UMK, pemerintah menuangkan ketentuan dalam Peraturan Pemerintah 8/2021 tentang permodalan awal, pendaftaran secara legal pendirian, perubahan dan pembubaran UMK. Hasil kajian menunjukkan bahwa peluang yang dinikmati UMK dengan berlakunya UU Ciptakerja adalah: 1) Dapat menikmati kemudahan melakukan pendaftaran melalui laman Kementrian Hukum dan HAM, https://ahu.go.id/ . 2) Setelah mendaftar akan mendapat sertifikat pendirian perusahaan sebagai bentuk usaha yang berbadan hukum yaitu Perseroan Perorangan. Sehingga pelaku UMKmemiliki akses untuk melakukan kolaborasi dengan pihak perbankan yaitu berupa peminjaman modal usaha, pendampingan usaha dan informasi. 3) Mendaftarkan perizinan untuk melindungi usahanya, bisa dilakukan secara gratis pada kementrian investasi, melalui "Online Single Submission/OSS (Perizinan Berusaha Terintegrasi Secara Elektronik). Pelaku UMK cukup mendaftar berupa nomer induk dari usahanya. Perizinan tidak rumit langsung selesai di level 
Pemerintahan Daerah, menurut aturan UU No. 23/2014: "Pemerintah Daerah", bisnis mikro dibantu oleh kabupaten \& kota, bisnis kecil dibina oleh provinsi, sedangkan bisnis menengah berskala nasional. 4) Kepala daerah diberikan kewenangan untuk menerbitkan izin mengikuti aturan PP5/2021: "Penyelenggaraan Perizinan Berusaha Berbasis Resiko" (Asmara,2021). 5) Mendapatkan sertifikasi halal agar produk dapat bersaing, dengan mendaftarakan secara gratis pada bit.ly/Sertifikat_Halal_UMI.Pelaku UMK melakukan perjanjian kesepakatan kerjasama dengan kementrian terkait, misalkan kementrian koperasi UKM dan Badan Usaha Milik Negara (BUMN) guna memasarkan dan mejajakan produknya dengan rencana kerja yang dibentuk oleh kementrian tersebut, yaitu PaDI (Pasar Digital) (Utami, 2021). 6) Mendaftarkan Merek usaha dan dipatenkan. Sebuah merek usaha dapat menentukan kesuksesan UMK karena konsumen akan lebih mudah mengenali produk atau jasanya dan lebih dipercaya. Merek bisa menjadi kunci kesuksesan UMK karena menjadikan produk kita melekat dalam benak konsumen. 7) Mendaftarkan Hak kekayaan Inteletual (HKI) atas produk yang dijual. Jika pelaku UMK lalai tidak mendaftarkan HKI, semua orang bisa memproduksi barangnya tanpa izin dan pelaku UMK akan kehilangan kesempatan untuk memperoleh keuntungan ketika orang lain menggunakan produk atau jasa hasil karyanya. UMK mempunyai basis data sederhana perlu dilakukan UMK sejak dini, perihal produk, pelanggan, rekanan bisnis, dengan adanya kejelasan data maka pelaku UMK bisa mempromosikan produknya dengan berbagai bentuk pemasaran agar pelanggan tertarik membeli. Juga untuk melindungi diri dari segala permasalahan hukum yang ada. 8) UMK yang mempunyai pinjaman pada pihak ketiga melakukan kesepakatan restrukturisasi kredit. Penataan ulang pinjaman oleh: OJK. Sektor UMK sampai Rp.369.8triliun berasal dari 5.84juta peminjam. (Listiyanto, 2020). Diwujudkan melalui pengurangan interest, penambahan termin, peringanan pinjaman awal, keringanan sangkutan interes ,pemberian pinjaman/pemodalan atau pertukaran pinjaman/pendanaan jadi penyertaan kapital temporer.(Bustomi, 2020). Dasar aturannya POJK No.11/POJK.03/2020: "Stimulus Perekonomian Nasional sebagai Kebijakan Counter Cyclical Dampak Penyebaran Coronavirus Disease 2019"(POJK Stimulus Dampak Covid-19). 9) Pemerintah melakukan arahan agar dapat saling berbagi informasi melalui pembentukanm komunitas/ organisasi/yayasan UMK atau bergabung dalam komunitas sesama pelaku UMK, sehingga saling berbagi informasi, misalkan pemerintah, lembaga terkait meluncurkan situs basis data UMK, bisa segera mendaftarkan diri sehingga disaat pemerintah memetakan kebutuhan UMK, bisa terakomodir, atau bisa mempunyai akses dengan projek pemerintah.

\section{Analisis}

Optimistis yang ditunjukkan oleh pelaku UMK perlu didukung oleh payung hukum yang kuat dan pasti guna menjadi patokan pelaksanaan UMK agar dapat mengimbangi keadaan dengan menghapus berbagai hambatan yang terjadi dalam pelaksanaan usaha, seperti di bidang hukum. Pemerintah mengeluarkan aturan berupa UU No. 11/2020 yang lebih dikenal dengan UndangUndang Cipta Kerja (UU CK). Aturan ini memudahkan UMK bergerak dengan platform baru, yaitu dapat membentuk perseroan perseorangan. Isi UU CK menjadi payung hukum bagi UMK sebagai pelaksanaan filosofi bangsa Indonesia, sila kelima yaitu keadilan sosial. Memberikan kesempatan yang sama bagi seluruh tataran bidang usaha baik usaha bermodal besar, menengah maupu UMK. Alasan dibentuknya UU CK adalah guna merealisasikan maksud pendirian Pemerintah Negara Indonesia \& melahirkan masyarakat Indonesia yang sejahtera, adil, dan makmur berdasar Pancasila, UUD'45. Melalui cipta kerja negara berupaya memenuhi kepentingan pekerjaan \& penghidupan sederajat juga berdaya guna menyerap pekerja yang sebanyak-banyaknya guna menunjang cipta kerja dibutuhkan adaptasi beraneka ragam perspektif sistematisasi yang berkelindan dengan 
keringanan, proteksi, pemantapan koperas \& UMKM dilaksanakan dengan merubah perundangan bidang yang tidak mengakomodasi terwujudnya penyelarasan dalam menanggung laju cipta kerja, jadi dibutuhkan pintasan hukum sehingga diperlukan terobosan hukum yang dapat membereskan bermacam persoalan dari banyak perundangan menjadi satu perundangan secara komprehensif.

Pemerintah terhadap UMK melalui UU CK sudah melakukan kemudahan dan perlindungan UMK dalam bidang hukum, antara lain dalam Pasal 153, Pasal 153A-153J UU Ciptaker. Upaya tersebut menimbulkan gairah bagi UMK, dapat dilihat hasilnya pada peningkatan jumlah BTI Micro \& SME Index (BMSI). UMK semakin optimis terhadap prospek usahanya yang ditunjukkan dengan BMSI terupdate tercatat peningkatan bermakna dalam "Indeks Aktivitas Bisnis"(IAB), "Indeks Ekspektasi Aktivitas Bisnis" (IEAB) \& "Indeks Sentimen Bisnis”(ISB) tiap kwartal 2021 dibanding kwartal IV tahun 2020.

Namun agar bisa optimal keefektifan UU CK sehingga pelaku pasar bisa bertahan dan tumbuh saat pandemi maka pelaku UMK harus melakukan teruji pada saat pelaku UMK melakukan upaya hukum selama pandemi berlangsung dan agar UMK dapat bertahan saat pandemi harus mengupayakan pemodalan dan sejumlah upaya hukum dengan mendaftarkan usahanya; mendaftarkan perizinan, sertifikasi halal, mendaftarkan merek. Sehubungan dengan hal tersebut maka penulis meneliti dampak pandemi covid-19 perspektif UU CK dalam memayungi pelaku UMK dan upaya hukum yangg dilakukan UMK agar bisa bertahan juga maju pada masa pandemi berlangsung. Dengan memahaminya maka UU CK akan menjadi tongak perubahan UMK untuk naik kelas dan berjaya baik didalam maupun di luar negeri

Upaya pemerintah perlu dilakukan pemerintah agar kehadiran UMK yang dianggap menjadi potensi dasar dan dapat memberikan kontribusi besar bagi perekonomian nasional tercapai sesuai keberadaannya. Walaupun covid-19 menimbulkan beragam kesulitan yang menghambat usaha UMK, namun karena peluang UMK masih dapat berkembang luas, maka upaya pemerintah dibutuhkan untuk memberikan peluang berupa bidang, usaha apa saja yang bisa menjadi bisnis UMK. Para pelaku UMK dituntun untuk terus berinovasi menciptakan sesuatu yang bukan hanya sekedar menjadi kebutuhan masyarakat saja. UMK diharapkan mampu untuk melihat dan mendayagunakan berbagai sarana tersedia medsos jadi platform pemasaran guna meningkatkan usaha UMK, juga finansial dan peluang pasar global paling tidak di pasar ASEAN.

\section{KESIMPULAN DAN SARAN}

\section{Kesimpulan}

Pandemi Corona hampir berjalan 2 (dua) tahun berdampak pada tatanan kehidupan masyarakat dunia. Indonesia juga merasakan dampak pandemi covid-19 terutama pada bidang perekonomian, manufaktur, dan UMK. Mayoritas pelakunya adalah warga menengah ke bawah terkena imbas yang sangat besar akibat pandemi ini. Sebagai pemberi masukan tertinggi ekonomi nasional juga bisa diandalkan dalam menyerap pegawai, mensubstitusi bahan setengah jadi, maka dalam kondisi krisis ekonomi karena pandemi yang berkepanjangan, sektor UMK perlu diberdayakan secara special. Sejumlah persoalan klasik yang membelit UMK, diantaranya permodalan, hutang yang tidak dapat dilunasi, persetujuan izin, pendistribusian, manajemen data dan peluang tender pemerintah. Kenyataan bahwa peraturan UMK terbagi pada banyak peraturan peundangan, berdampak pada cara pemantapan kinerja UMK yang tersebar, tidak bertautan \& memperlambat penanaman modal.

Padahal kehadiran UMK dianggap menjadi potensi dasar yang bisa memberikan kontribusi besar bagi bisnis nasional. Pada pandemi ini peluang UMK untuk terus bisa berkembang masih cukup luas dikarenakan tidak adanya keterbatasan bidang, usaha bidang apa saja bisa menjadi peluang bisnis 
UMK, Dalam kondisi pandemi berlanjut,UMK di tuntun untuk terus berinovasi untuk menciptakan sesuatu yang bukan hanya sekedar menjadi kebutuhan masyarakat saja. UMK diharapkan mampu untuk melihat dan memaksimalkan pengunaan medsos jadi platform pemasaran guna untuk meningkatkan usaha UMK (Sibarani,2020).

Pada saat pandemi UMK diberdayakan maksimal sebagai upaya pemerintah dalam pemulihan perekonomia. UMK berperan sangat penting pada perdagangan nasional. Upaya tersebut dilakukan adanya keterlibatan penduduk sebagai pelaku UMK secara langsung, juga jadi media memeratakan ekonomi khalayak ramai, pengentasan kemelaratan \& wahana penyerapan anggaran bagi negara.

\section{Saran}

Perlu adanya komitmen pemerintah untuk menunjang keberlangsungan UMK melalui finansial, promosi, pemasaran, menghimbau lembaga-lembaga terkaittermasuk pemerintah daerah sampai pada tataran yang rendah seperti kelurahan untuk turut memberikan dukungan bagi perkembangan UMK agar bertahan dan/atau berkembang walaupun Pandemi covid-19 sudah berakhir guna memberdayakan UKM masuk ke pasar global paling tidak ke pasar ASEAN.

Upaya pemerintah telah dilakukan melalui landasan hukum berusaha namun demi kepastian hukum diharapkan adanya satu aturan saja yang akan menjadi landasan berusaha bagi UMK, demikian pula ada keinginan, kegairahan dari UMK untuk mengembangkan dirinya agar dapat bertahan, bahkan berkembang memasuki pasar ASEAN. Karena Sebaik apapun badan usaha yang berbadan hukum dipersiapkan oleh pemerintah, sekhusus apapun regulasi yang diberikan, semudah apapun pendiriannya, jika pelaku Usaha Mikro Kecil (UMK) tidak siap atau tidak mampu menerapkan dalam sistem bisnisnya maka tidak memberikan efek positif atau akan berhenti sebelum tujuan mulianya tercapai. Jadi penulis menyarankan adanya kerjasama dengan pemerintah daerah untuk melakukan pembinaan penerapan sistem Perseroan Perorangan dengan pendekatan dari tingkat yang terkecil dari pemerintahan yaitu Lurah, dimana Lurah mendelegasikan ke ketua RT/RW masingmasing di wilayahnya. Muara akhir dari kemudahan berusaha yang dituangkan pemerintah dalam aturan UUCK bagi UMK adalah UMK dapat mengembangkan usahanya dengan mendapat pinjaman modal dari Bank, maka juga berdampak resiko khususnya bagi pendana. Sehubungan dengan hal tersebut pemerintah selayaknya membuat peraturan yang menyeimbangkan antara kemudahan berusaha dan perlindungan pihak ketiga atau kreditur. Respons terhadap pemberdayaan pemerintah, maka Pelaku UMK harus melakukan perubahan pola pikir dan pola kerja jika ingin bertahan atau bahkan mengalami pertumbuhan dimasa pandemi Covid-19, yaitu dengan jeli melihat peluang, reka baru, siap disegala kondisi mempersiapkan diri untuk skenario terburuk, kecepatan pengiriman, memaksimalkan gadget (handphone), marketplace, electronic commerce dan semua karakteristiknya. Pelaku UMK juga harus fokus dibisnisnya, jika selalu berganti jenis usaha akan menjadikan Usaha Mikro Kecil tidak bisa berkembang. UMK sebagai pendukung perekonomian nasional selayak mendapat perhatian \& dukungan penuh dari Pemerintah Indonesia.

\section{Ucapan Terima Kasih}

Bapak Yuwono Prianto, S.H,M.H. selaku dosen pembimbing.

\section{REFERENSI}

Asmara, CG. (2021). "UMKM Investasi sampai Rp.5Miliar, Urus Izinnya Gratis!” CNBC INDONESIA. 9 Agustus https://www.cnbcindonesia.com/news/20210809095321-4267109/umkm-investasi-sampai-rp-5-miliar-urus-izinnya-gratis 
Bahtiar, R A. (2021). "Dampak Pandemi Covid 19 Terhadap Sektor Usaha Mikro, Kecil dan Menengah Serta Solusinya".Info Singkat,Vol.XIII,No.10/II/Puslit/Mei/2021 Bustomi. (2020). "Ini Strategi UMKM Bertahan Di Tengah Pandemi”. Top Business. 5 Mei Data UMKM 2018-2019.

Kementrian Koordinator Bidang Perekonomian Republik Indonesia. 2021. UMKM Menjadi Pilar PentingDalamPerekonomianIndonesia.Jakarta,5mei https://ekon.go.id/publikasi/detail/2969/umkm-menjadi-pilar-penting-dalam-perekonomianindonesia

Listiyanto, E (2020). “Optimisme UMKM Melalui Restrukturisasi Kredit. Investor.ID, 3 Desember https://investor.id/opinion/230062/optimisme-umkm-melalui-restrukturisasi-kredit

Marlina, L. (2020). "Peluang dan Tantangan UMKM Dalam Upaya Memperkuat Perekonomian Nasional Tahun 2020 di Tengah Pandemi Covid 19”. Jurnal Ekonomi, Vol.22, No.2, Juni

Soerjono, S \& Mamudji, S (2021). “Penelitian Hukum Normatif Suatu Tinjauan Singkat. RajaGrafindo Persada, Depok.

Indonesia. (2021). Peraturan Pemerintah Nomor 8 Tahun 2021 tentang Modal Dasar Perseroan Serta Pendaftaran Pendirian, Perubahan, dan Pembubaran Perseroan yang Memenuhi Kriteria Untuk Usaha Mikro dan Kecil. LN.2021/No.18, TLN No.6620.

Indonesia, POJK. (2020). "POJK Nomor 11/POJK.03/2020 tentang Stimulus Perekonomian Nasional sebagai Kebijakan Counter Cyclical Dampak Penyebaran Coronavirus Disease 2019 (POJK Stimulus Dampak Covid-19).

Indonesia, PP (2021). Peraturan Pemerintah nomor 8 Tahun 2021 tentang Modal Dasar Perseroan serta Pendaftaran Pendirian, Perubahan, dan Pembubaran Perseroan Yang Memenuhi Kriteria Untuk Usaha mikro dan Kecil.

Indonesia, UU (2008). Undang-Undang Nomor 20 Tahun 2008 tentang Usaha Mikro, Kecil, dan Menengah. LN.2008/ No.93, TLN No.4866.

Indonesia, UU. (2014). Undang-Undang Nomor 23 Tahun 2014 tentang Pemerintah Daerah. LN.2014/No.244, TLN No.5587.

Indonesia, UU. (2020). Undang-Undang Nomor 11 Tahun 2020 tentang Cipta Kerja. LN. No.2020/No.245,TLN No.6574.

Sibarani, S. (2020). "Inovasi Produk Bagi UMKM Di Tengah Pandemi Covid-19 Berdasarkan Sudut Pandang Hukum dan Demokrasi”. Vol.2 (1), 256-263.

Suharso \& Retnoningsih, A. (2014). Kamus Besar Bahasa Indonesia. Widya Karya, Semarang.

Utami, SS . (2021). "Digitalisasi Jadi Kunci UMKM Bertahan Di Tengah Pandemi”. Medcom,id. 9 Mei https://www.medcom.id/ekonomi/bisnis/RkjlmA9N-digitalisasi-jadi-kunci-umkm-bertahan-ditengah-pandemi

Laoly, Y. (2021). "UU Cipta Kerja Mungkinkan PT Didirikan Tanpa Akta Notaris, Menkumham: Ini Komitmen Pemerintah Wujudkan Kemudahan Berusaha". Yasonnalaoly.com, 22 februari. https://yasonnahlaoly.com/tag/kemenkumham/ 
Seminar Nasional Hasil Penelitian dan Pengabdian Kepada Masyarakat 2021

Pengembangan Ekonomi Bangsa Melalui Inovasi Digital Hasil Penelitian dan

Pengabdian Kepada Masyarakat

Jakarta, 21 Oktober 2021
SENAPENMAS

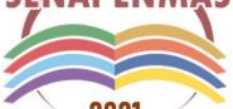

2021

(halaman kosong) 